RU Проблемы передачи и гармонизации терминологии в сфере земледелия в России и за рубежом на примере термина “no-till”

Лысенко Н. Е.

Аннотация. Цель исследования - уточнить дефиницию и определить степень терминологической синонимии агрономических терминов на примере американского термина "no-till" и российского термина «прямой посев», обусловленных различными подходами в земледелии. Исследование проводится на материале глоссариев и новостных обзоров на интернет-сайтах сельскохозяйственных организаций и библиотеки eLIBRARY. Научная новизна работы определяется сравнительносопоставительным подходом, с позиции которого выполнен лингвистический, статистический и понятийный анализ дефиниций этих терминов, установлена степень синонимичности и частотность употребления. В результате определено, что российская и американская агрономические терминологии отличаются наличием общих характеристик, присущих данной области знания.

\title{
Issues of Terminology Translation and Harmonisation in the Field of Agriculture in Russia and Abroad by the Example of the Term "no-till"
}

\author{
Lysenko N. E.
}

\begin{abstract}
The purpose of the study is to clarify the definition and determine the degree of terminological synonymy of agronomic terms which are conditioned by different approaches in agriculture, using the American term "no-till” and the Russian term «прямой посев» ('direct seeding') as examples. The research is carried out on the basis of the material of glossaries and news reviews found on websites of agricultural organisations and the portal eLIBRARY. Scientific novelty of the work is determined by a comparative-contrastive approach, from the standpoint of which a linguistic, statistical and conceptual analysis of the definitions of these terms are conducted, the degree of their synonymy and frequency are identified. As a result, it has been found that Russian agronomic terminology and the American one have common features inherent in this knowledge area.
\end{abstract}

\section{Введение}

В настоящее время терминологические исследования приобретают особую актуальность в связи с процессами международного сотрудничества, развитием науки и технологий. Вопросы изучения функционирования отраслевой терминологии, выработка дефиниций для новых терминов, гармонизация терминологии в соответствии с международными стандартами представляют интерес не только для терминоведения и языкознания, но и для сельского хозяйства, в частности, в сфере земледелия. Ученые и производственники отмечают необходимость четкого, «родного» определения новых терминов, т.к. в агрономической среде новые термины понимаются по-разному в связи с отсутствием их дефиниций в глоссариях и ГОСТах [10]. Американские ученые также пишут о необходимости гармонизации терминов, т.к. существуют определения, которые противоречат друг другу: “...we identified instances where multiple, often conflicting, definitions existed... then sought to harmonize these various definitions to produce a single meaning for each term” [17, p. 7]. / «...мы нашли термины со множественными, взаимоисключающими определениями и гармонизировали их» (пер. с англ. автора. - Н. Л.).

Исследование проблем передачи и гармонизации терминологии в сфере земледелия в России и за рубежом, на наш взгляд, представляется актуальным в связи с развитием науки и технологий, интересом аграриев к новой технологии и терминологии, в частности к термину “no-till”, и, как следствие, в связи с недостаточной

Научная статья (original research article) । https://doi.org/10.30853/phil210443

(๔) 2021 Авторы. 000 Издательство «Грамота» (๔ 2021 The Authors. GRAMOTA Publishers). Открытый доступ предоставляется на условиях лицензии СС ВY 4.0 (open access article under the CС BY 4.0 license): https://creativecommons.org/licenses/by/4.0/ 
изученностью лингвистических явлений в этой сфере. Для реализации поставленной цели необходимо решить следующие задачи: 1) изучить дефиницию термина “no-till” в российских и зарубежных глоссариях, ГОСТе, новостных обзорах на профессионально ориентированных сайтах как технологии, элемента технологии или системы земледелия; 2) выявить частотность употребления тематической группы “no-till” и «прямой посев» в России и за рубежом на профессионально-ориентированных сайтах и степень синонимичности этих понятий; 3) определить количество словарей-справочников и глоссариев по земледелию с дефиницией термина “no-till”.

Исследование выполнено с применением метода контент-анализа, статистического метода, метода лингвистического анализа, сравнительно-сопоставительного метода.

В качестве материала для лингвистического анализа взяты электронные текстовые ресурсы - глоссарии, словари [9; 10; 12; 16], ГОСТ по земледелию [3], новостные обзоры, представленные на сайтах Министерства сельского хозяйства Российской Федерации [10], Министерства сельского хозяйства США [18], Продовольственной и сельскохозяйственной организации ООН (ФАО) (англ. Food and Agriculture Organization, FAO) [13; 14], материалы круглого стола ежегодной международной выставки «Золотая осень» [6], научной электронной библиотеки ELIBRARY [8].

Теоретической базой исследования по терминологии в сфере сельского хозяйства послужили работы Ф. Г. Бакирова, Д. Г. Полякова, А. В. Халина, А. А Баландиной [1], Т. Н. Даньковой [4], М. М. Русаковой, П. Л. Горелик, Н. В. Мавриной [11], М. П. Томпсона, Т. Циммермана, Д. Миндара, М. Табер [17], М. Д. Ероховой, А. Д. Орлинского [5], материалы круглого стола ежегодной международной выставки «Золотая Осень» [6].

Практическая значимость исследования заключается в возможности использования его результатов в спецкурсах по терминоведению, при составлении справочников и глоссариев по почвоведению, а также на профессионально ориентированных семинарах и круглых столах.

\section{Основная часть}

Проблему дефиниции термина “no-till” и необходимость его унификации признают российские и зарубежные ученые. С точки зрения Т. Н. Даньковой, «русская терминология сельскохозяйственной сферы представляет собой сконструированную специалистами систему из сознательно отобранных или созданных слов и словосочетаний-терминов, а также терминов, заимствованных из других языков, служащую для изложения теории, описывающую научную отрасль» [4, с. 88]. М. Д. Ерохова и А. Д. Орлинский считают, что «многие терминологи, лексикографы и переводчики, следуя идеям языкового космополитизма, бездумно выбирают значения терминов, стоящие в начале синонимического ряда, или используют кальку с английского языка при создании новых терминов. Часто несколькими специалистами отдельно друг от друга разрабатывается несколько терминов для одного понятия, что вносит путаницу в использование того или иного термина. В результате... уже ощущается некоторый недостаток единообразной, унифицированной терминологии из-за отсутствия в России координирующего органа, ответственного за разработку и утверждение специальной лексики в этой области» [5, с. 3].

Одним из таких обсуждаемых терминов в сельском хозяйстве, который по-разному понимается в России и за рубежом в связи с отсутствием единой дефиниции, является технология no-till. Буквально это сочетание переводится с английского языка как «не пахать» и используется для обозначения технологии выращивания растений без обработки почвы. В англо-русском словаре по почвоведению этот термин переводится как «нулевая технология обработки почвы», «гербицидная обработка почвы», «химическая обработка почвы» [9]. Эта технология определяет суть и содержание системы земледелия, в которой почва не обрабатывается. Определение «технология» является условным, т.к. в настоящее время в России среди ученых и производственников-агрономов наблюдается разное понимание термина “no-till”, обозначающего возделывание сельскохозяйственных культур без обработки почвы, который в мире называют «технология», «элемент технологии», «прямой посев», «система нулевой обработки почвы». «Применение технологии No-till в целом... по стране ограничено. Объясняется это... в том числе трудностями, вызванными недостаточным представлением сути технологии, обусловленным большим полем интерпретаций понятия No-till» $[1$, c. 50].

Хотя родоначальником нулевой технологии земледелия в России является И. Е. Овсинский, который с 1871 года начал практические опыты по выращиванию сельскохозяйственных культур без глубокой вспашки, на практике эта технология получила наибольшее распространение в Америке и Канаде в связи с засушливым климатом, пыльными бурями, истощением земельных ресурсов, а сейчас внедряется в России.

Необходимость дефиниции термина "no-till” возникает и в системе агрострахования в России. При наступлении страхового случая четко должно прослеживаться соблюдение технологий. Технология подразумевает вспашку, культивацию и т.д. Если человек, который застраховал посевы, не выполнил ряд мероприятий, он нарушает традиционную технологию. Люди, которые используют технологию no-till или другие альтернативные технологии, не знают, что делать в такой ситуации в связи с отсутствием гармонизированных дефиниций.

Таким образом, формы и технологии почвозащитного земледелия развиваются, а терминология остается прежней.

В ГОСТе по земледелию [3] отсутствует дефиниция термина “no-till”, т.к. в период разработки ГОСТа в 1991 г. этот термин не использовался. Но там указана дефиниция термина «прямой посев» - «технология без предварительной обработки почвы». Посев - размещение семян по площади пашни на установленную глубину. Пашня относится к категории земель, которые систематически обрабатываются. Получается, что посевы 
или земли, которые механически не обрабатываются, не являются пашнями, что является противоречием в дефиниции применительно к термину “no-till”.

В отличие от официальных документов, где используется термин «прямой посев», термин “nо-till” как технология, система и метод часто используется в новостных обзорах. В сочетании «технология no-till» найдено 44 результата по запросу в поисковой строке, «нулевая технология обработки почвы» - 49 результатов. Сочетание «система no-till» используется реже - 31 результат, присутствует также комбинированный вариант термина, например, «система нулевой обработки почвы» (система no-till). В русском языке появился профессиональный жаргон, образованный от термина “no-till” - ноутильщики, т.е. наблюдается процесс языковой ассимиляции заимствования. Использование сочетания «технология прямого посева» происходит вдвое чаще - 105 результатов. Это можно объяснить исторически сложившимися традициями в русской классической системе терминологии в земледелии.

На сайте Министерства сельского хозяйства США [18] терминологическое сочетание “no-till technology" используется чаще, чем сочетание “no-till system”. При анализе сочетания “direct seeding” в значении «прямой посев» выявлено, что этот термин используется в одной тематической группе с термином “nо-till”, как в примере “No-Till / Strip Till / Direct Seed” / «беспахотный посев / ленточный посев / прямой посев», но не идентичен ему. В Оксфордском словаре дана общая формулировка технологии: "Planting a crop without preparing the ground in advance or working it afterwards. Also known as zero till” [16] / «посадка культуры в необработанную почву или с последующей обработкой, известная как “нулевая обработка”». Термин «прямой посев или direct seeding» в нем понимается как “A forestry term relating to the method of sowing of seed directly onto the area of ground for the proposed crop" [Ibidem] / «термин, используемый в лесоводстве, метод посева культуры прямо в почву» - термин, используемый в лесном хозяйстве, а не агрономии. Это подтверждает вывод о том, что понятия “no-till” и «прямой посев / direct seeding» не являются взаимозаменяемыми, и свидетельствует о низкой степени их синонимичности.

На сайте Продовольственной и сельскохозяйственной организации ООН (ФАО) в глоссарии Organic Agriculture (органическое сельское хозяйство) термин “no-till” понимается как система или форма посадки злаковых культур: "System of planting (seeding) crops into untilled soil by opening a narrow slot... No other soil tillage is done", “No-till or no-tillage describes a form of cropping...” [14]. / «Система посадки культур в невспаханную почву в узкие борозды». Термины «прямой посев / direct seeding», “no-till” трактуются как синонимы, т.е. близкие или совпадающие по значению: “...the term direct seeding is understood in CA (conservation agriculture) systems as synonymous with no-till farming, zero tillage, etc. One of the advantages of direct seeding is that together with other CA practices, it increases the resilience of the agrosystem against climate associated risks" [13]. / «...термин прямой посев понимается в почвозащитном и ресурсосберегающем земледелии как синоним терминов беспахотное земледелие, нулевая обработка и т.д. Одно из его преимуществ в том, что он повышает стойкость агросистемы к риску климатических изменений». Эксперты организации относят технологию no-till к почвозащитному ресурсосберегающему земледелию и понимают ее как систему земледелия со свойственными только ей характеристиками. По частотности результатов в запросах преобладает термин “no-till system”, т.e. термин "no-till” понимается преимущественно как система, а не технология.

При трактовке терминов «прямой посев» и «Ноу-тилл» эксперты компании Агромир понимают прямой посев как один из ведущих принципов, применяемых при реализации технологии no-till. Он предполагает внесение семян и удобрений в неподготовленную почву и реализуется с использованием сеялок прямого посева. Таким образом, прямой посев - это только часть, один из элементов технологии no-till [2].

B научной электронной библиотеке eLIBRARY [8] представлены научные публикации с термином “no-till”, но значительно чаще используется термин «прямой посев»- 72512. В большинстве публикаций он рассматривается как отдельная технология. Есть научные публикации ученых-агрономов, в которых объясняется неправильность понимания этих терминов как полных синонимов: «Сложности в понимании сути технологий возникают и в связи с тем, что No-till используют как синоним термина “прямой посев”. На самом, деле общим для них является только то, что посев в обоих случаях осуществляется по не обработанной с осени почве, т.е. по нулевой обработке. Главное же отличие между понятиями заключается в том, что прямой посев в севообороте может применяться эпизодически... В технологии No-till основная обработка в севообороте исключается полностью и обработка почвы (технология) трансформируется в систему земледелия. Прямой посев (нулевая обработка) может классифицироваться только как прием или технология. При этом игнорируется и тот факт, что прямой посев и нулевая обработка почвы также не одно и то же... Прямой посев (нулевая обработка почвы) значительно отличаeтcя om No-till по воздействию на плотность почвы, влиянию на водопотребление и урожайность культур, что дает основание утверждать - это разные агроприемы, а значит, и понятия» $[1$, с. 50-51, 53].

На сайте Минсельхоза России представлены преимущественно словари терминов и определений [10; 12]. Глоссариев на сайте не представлено. Исторически глоссарий является предшественником словаря. Отличие глоссария от словаря заключается в том, что он дает толкование терминов по какой-либо дисциплине, «глосса (греч.) - перевод или толкование непонятного слова» [7, с. 107], “a list of technical or special words, especially those in a particular text, explaining their meanings” [15] / список технических или профессиональных слов с толкованием. На англоязычных профессионально направленных сайтах представлены большей частью глоссарии, а на русскоязычных сайтах - словари терминов и определений $[9 ; 10 ; 15]$. При анализе структуры и содержания глоссариев и словарей терминов и определений на профессионально ориентированных сайтах по сельскому хозяйству отличий в их структуре и содержании не выявлено, в них представлен унифицированный понятийный аппарат терминов и определений. Следует отметить, что на сайтах сельскохозяйственных 
организаций зарубежных стран размещено значительно большее количество глоссариев. Для российских аграриев официальным унифицированным документом является ГОСТ терминов и определений, но в глоссариях содержится актуальная информация для его обновления.

На сайте Продовольственной и сельскохозяйственной организации ООН (ФАО) следует отметить большое количество глоссариев - 79200.

На сайте Министерства сельского хозяйства США можно найти более 240 глоссариев по сельскому хозяйству, но дефиниция понятия “no-till” в них не представлена.

На сайте научной библиотеки eLIBRARY.RU представлено достаточное количество глоссариев (более 44 тыс.), из них найдено 15 глоссариев по охране окружающей среды, природопользованию, 20 словарей-справочников по земледелию. Поиск дефиниции затрудняет тот факт, что не все словари и глоссарии находятся в открытом доступе, а в доступных источниках дефиниция не представлена.

B разделе “FAO Term Portal” на сайте Продовольственной и сельскохозяйственной организации ООН (ФАО) можно предложить свой термин онлайн [14], чего нет на других профессионально ориентированных сайтах.

Таким образом, следует отметить недостаточное количество глоссариев и словарей-справочников по земледелию на российских профессионально ориентированных сайтах. На аналогичных зарубежных сайтах глоссариев и словарей по земледелию представлено значительно больше, и они в открытом доступе онлайн, но дефиниции искомых терминов отличаются от их традиционного понимания российскими учеными-агрономами, что указывает на необходимость гармонизации терминологии.

Результаты поиска дефиниций к термину “no-till” как технологии, системы, метода, а также термина «прямой посев» и анализа глоссариев на сайтах Минсельхоза РФ и США, ФАО и электронной библиотеки eLIBRARY представлены в Таблице 1 .

Таблица 1. Результаты поиска дефиниций к терминам “по-till” и «прямой посев»

\begin{tabular}{|c|c|c|c|c|}
\hline $\begin{array}{c}\text { Количество } \\
\text { найденных результатов } \\
\text { на сайте организации } \\
\end{array}$ & Минсельхоз РФ & Минсельхоз США & ФАО & eLIBRARY \\
\hline no-till как технология & 44 & 600 & 15300 & 11 \\
\hline no-till как система & 31 & 530 & 22600 & 9 \\
\hline no-till как метод & 11 & 400 & 12200 & 4 \\
\hline прямой посев / direct seed & 105 & 360 & 12100 & 72512 \\
\hline $\begin{array}{l}\text { Количество глоссариев/ } \\
\text { словарей по земледелию }\end{array}$ & 4 & 240 & 25700 & $\begin{array}{c}15 \text { глоссариев } \\
20 \text { словарей- } \\
\text { справочников }\end{array}$ \\
\hline
\end{tabular}

\section{Заключение}

Подводя итог лингвистического исследования, можно сделать следующие выводы.

Несмотря на существующие различия в дефиниции понятия “no-till” в российских и зарубежных глоссариях, ГОСТе, новостных обзорах на профессионально ориентированных сайтах как технологии, элемента технологии или системы земледелия, в большинстве случаев англоязычные и российские дефиниции совпадают в понимании термина “no-till” как технологии в земледелии, а не ее элемента.

Частотность употребления термина «прямой посев» российским научным сообществом значительно выше, чем термина "no-till”, что связано с использованием классической отечественной терминологии в системе земледелия и тем, что термин “no-till” появился сравнительно недавно. Особенности понимания синонимичных терминов “no-till” и «прямой посев» американскими, европейскими и российскими ученымиагрономами проявляются в отличающихся способах их дефиниций. Термин «прямой посев / direct seeding» не является взаимозаменяемым синонимом к термину “no-till”, а понимается как отдельная технология.

В ходе сравнительного обзора англоязычных и русскоязычных глоссариев и словарей-справочников было установлено, что количество и содержание глоссариев не являются достаточными для всестороннего понимания термина “no-till”. Наиболее полная его дефиниция представлена в онлайн-глоссарии на сайте ФАО и научных публикациях в открытом доступе в электронной библиотеке eLIBRARY. B то же время дефиниции в глоссариях нуждаются в гармонизации, т.к. российские ученые-агрономы не всегда согласны с представленными определениями термина в отношении российского земледелия, как в случае дефиниции понятий “no-till” и «прямой посев» как синонимичных или относящихся к лесоводству (the term direct seeding is understood in CA systems as synonymous with no-till farming, zero tillage; direct seeding is a forestry term).

Перспективы дальнейшего исследования дефиниции агрономических терминов в российской и зарубежной аграрной науке мы видим в более детальном изучении синонимичных и смысловых связей между ними как лингвистами, так и учеными-агрономами для осторожного, правильного и эффективного применения в сельском хозяйстве России. Перспективными представляются также разработка и гармонизация терминологии в онлайн-глоссариях по земледелию в открытом доступе на основе отечественного и международного опыта при сотрудничестве лингвистов и аграриев для правильного понимания и выбора зарубежных технологий и методов в земледелии и для внесения обновлений в ГОСТ. 


\section{Источники | References}

1. Бакиров Ф. Г., Поляков Д. Г., Халин А. В., Баландина А. А. Прямой посев и No-till в Оренбуржье // Известия Оренбургского государственного аграрного университета. 2018. № 5 (73). С. 50-54.

2. Блог компании Агромир [Электронный ресурc]. URL: http://blog.agromir-notill.com (дата обращения: 28.07.2021).

3. ГОСТ 16265-89. Земледелие. Термины и определения [Электронный ресурс]: утв. и введ. в действие Постановлением Государственного комитета СССР по управлению качеством продукции и стандартам от 25.12.89 № 4093. URL: https://docs.cntd.ru/document/1200022975 (дата обращения: 25.07.2021).

4. Данькова Т. Н. Основные тенденции развития русской сельскохозяйственной терминологии // Известия Волгоградского государственного педагогического университета. 2009. № 2 (36) С. 85-88.

5. Ерохова М. Д., Орлинский А. Д. Глоссарий фитосанитарных терминов и каверзы перевода международных фитосанитарных текстов на русский язык // Защита и карантин растений. 2020. № 8. С. 3-5.

6. Концепция почвозащитного и ресурсосберегающего земледелия: гармонизация терминологии с международными стандартами и перспективы внедрения в России [Электронный ресурс]: материалы круглого стола ежегодной международной выставки «Золотая Осень» (23 марта 2021 г.). URL: https:/agriecomission.com/ base/487-kruglyi-stol-koncepciya-pochvozashchitnogo-i-resursosberegaushchego-zemledeliya-garmonizaciyaterminologii-s-mejdunarodnymi-standartami-i-perspektivy-vnedreniya-v-rossii (дата обращения: 17.04.2021).

7. Лингвистический энциклопедический словарь / гл. ред. В. Н. Ярцева. М.: Советская энциклопедия, 1990. 685 с.

8. Научная электронная библиотека eLIBRARY.RU [Электронный ресурc]. URL: https://www.elibrary.ru/(дата обращения: 20.07.2021).

9. Онлайн-словарь Мультитран [Электронный ресурс]. URL: https://www.multitran.com (дата обращения: 25.07.2021).

10. Официальный сайт Министерства сельского хозяйства Российской Федерации [Электронный ресурс]. URL: https://mcx.gov.ru (дата обращения: 25.07.2021).

11. Русакова М. М., Горелик П. Л., Маврина Н. В. Строительная терминология в рекламном дискурсе: лингвопрагматический аспект // Филологические науки. Вопросы теории и практики. 2021. Т. 14. Вып. 7. С. 2279-2283.

12. Словарь терминов и определений, используемых в сортоиспытании сельскохозяйственных растений / под ред. В. И. Старцева. М.: Росинформагротех, 2019. 292 с.

13. Direct seeding equipment for tractors (Conservation Agriculture) [Электронный pecypc]. URL: http://www.fao. org/3/CA3010EN/ca3010en.pdf (дата обращения: 24.07.2021).

14. FAO Term Portal [Электронный ресурс]. URL: http://www.fao.org/faoterm (дата обращения: 27.07.2021).

15. Oxford Learner's Dictionaries [Электронный ресурс]. URL: https://www.oxfordlearnersdictionaries.com (дата обращения: 25.07.2021).

16. Oxford Reference [Электронный ресурс]. URL: https://www.oxfordreference.com (дата обращения: 25.07.2021).

17. Thompson M. P., Zimmerman T., Mindar D., Taber M. Risk terminology primer: Basic principles and a glossary for the wildland fire management community. Gen. Tech. Rep. RMRS-GTR-349. Fort Collins: U. S. Department of Agriculture, Forest Service, Rocky Mountain Research Station, 2016. 13 p.

18. United States Department of Agriculture [Электронный ресурс]. URL: https://usdasearch.usda.gov (дата обращения: 25.07.2021).

\section{Информация об авторах | Author information}

RU Лысенко Наталья Евгеньевна ${ }^{1}$, к. пед. н.

${ }^{1}$ Орловский государственный аграрный университет имени Н. В. Парахина

EN Lysenko Natal'ya Evgen'evna ${ }^{1}, \mathrm{PhD}$

${ }^{1}$ Orel State Agrarian University

${ }^{1}$ n.lysenko@inbox.ru

\section{Информация о статье | About this article}

Дата поступления рукописи (received): 01.08.2021; опубликовано (published): 30.09.2021.

Ключевые слова (keywords): гармонизация терминологии; дефиниция; глоссарий; синонимы; terminology harmonisation; definition; glossary; synonyms. 